\title{
Ação do óleo essencial de eucalipto na micorrização e no estabelecimento de Eucalyptus grandis em solo contaminado por cobre
}

\author{
Ricardo Bemfica Steffen ${ }^{1}$, Zaida Inês Antoniolli', Gerusa Pauli Kist Steffen ${ }^{1}$, Rodrigo Josemar Seminoti Jacques ${ }^{1}$, Rodrigo Ferreira da Silva ${ }^{2}$ \\ ${ }^{1}$ Universidade Federal de Santa Maria (UFSM), Departamento de Solos, Centro de Ciências Rurais, Bairro Camobi, 1.000, CEP 97105-900, Santa Maria, RS, Brasil. \\ ${ }^{2}$ Universidade Federal de Santa Maria (UFSM) - Cesnors, Curso de Agronomia, Linha Sete de Setembro s/n, BR 386, Km 40, CEP 98400-000, Frederico \\ Westphalen, RS, Brasil.
}

"Autor correspondente:

bemfica_steffen@yahoo.com.br

Termos para indexação:

Metais pesados

Metabólitos secundários

Fungos ectomicorrízicos

Index terms:

Heavy metals

Secondary metabolites

Ectomycorrhizal

Histórico do artigo:

Recebido em 20 abr 2011

Aprovado em 15 ago 2011

Publicado em 30 ago 2011

doi: 10.4336/2011.pfb.31.67.245
Resumo - A utilização do óleo essencial de eucalipto pode otimizar o crescimento de isolados ectomicorrízicos, os quais auxiliam o estabelecimento de essências florestais em solos contaminados por cobre. O trabalho teve por objetivo determinar a melhor forma de aplicação do óleo essencial de eucalipto na formação de mudas de Eucalyptus grandis micorrizadas e sua influência no estabelecimento dessas mudas em solo contaminado por cobre. Utilizou-se o fungo ectomicorrízico (fECM) Pisolithus microcarpus. As formas de aplicação do óleo essencial foram avaliadas em casa de vegetação, por meio de seis tratamentos. Posteriormente, as mudas foram transplantadas e avaliadas em solo contaminado por cobre, em condições de casa de vegetação e campo. Determinou-se altura, diâmetro, massa fresca e seca da parte aérea e raízes, teor de cobre na planta, colonização micorrízica e sobrevivência no campo. O óleo essencial de $E$. grandis favorece o crescimento de mudas de eucalipto micorrizadas, principalmente quando aplicado diretamente no substrato. A aplicação do óleo essencial aumenta a colonização micorrízica, favorecendo o crescimento e a sobrevivência das mudas em condições de casa de vegetação e campo.

\section{Eucalyptus essential oil action on mycorrhizal colonization and the establishment of Eucalyptus grandis in soil contaminated by copper}

\begin{abstract}
The use of eucalyptus essential oil can optimize the growth of ectomycorrhizal isolates, which aid the establishment of forest species in soils contaminated by copper. The study aimed to determine the best application of eucalyptus essential oil in the formation of mycorrhizal seedlings of Eucalyptus grandis and its influence on the establishment of these seedlings in soil contaminated by copper. It was used the ectomycorrhizal fungi (fECM) Pisolithus microcarpus. The application forms of the essential oil were evaluated in a greenhouse, by means of six treatments. Subsequently, the seedlings were transplanted and evaluated in soil contaminated by copper, greenhouse and field. It was determined height, diameter, fresh and dry weight of shoots and roots, copper content in plant, colonization and survival in the field. The essential oil of E. grandis supports the growth of mycorrhizal of eucalyptus seedlings, particularly when applied to the substrate. The application of essential oil increases the colonization, promoting growth and survival of seedlings under greenhouse conditions and field.
\end{abstract}




\section{Introdução}

Em áreas contaminadas por metais ocorrem danos ao meio ambiente devido à ação desses elementos sobre o solo, a água, a vegetação e os organismos que habitam o ecossistema. A maioria das plantas quando submetidas a substâncias químicas à base de cobre manifesta sintomas de toxidez como necrose e redução no crescimento do sistema radicular (Soares et al., 2000), mas também podem ocorrer necrose das folhas, desfolhamento precoce e diminuição do crescimento aéreo da planta (Grassi Filho, 2005).

Entre os metais pesados que podem estar presentes no ambiente com potencial de causar toxicidade à maioria dos organismos animais e vegetais, o cobre constitui fator limitante (Camargo et al., 2001; Turnau et al., 2001). As Minas do Camaquã, antiga e principal mineradora de cobre situada no Rio Grande do Sul, embora desativada, representa considerável potencial contaminante, devido aos elevados níveis de cobre presentes nas áreas de rejeito.

A utilização de microrganismos na biorremediação de solos contaminados por metais tem sido estudada como alternativa para viabilizar a recuperação dessas áreas degradadas (Grazziotti et al., 2003; Gadd, 2004; Amezcua-Allieri et al., 2005; Khan, 2006; Göhre \& Paszkowski, 2006). Dentre os microrganismos capazes de auxiliar no estabelecimento de plantas em áreas degradadas, destacam-se os fungos que formam associações ectomicorrízicas (fECM), propiciando aumento no volume de solo explorado pelas raízes e favorecendo a absorção e translocação de água e nutrientes do solo para a planta hospedeira (Smith \& Read, 2008). Em relação a solos contaminados por metais, os benefícios da inoculação das plantas com fungos ectomicorrízicos devem-se à proteção das raízes pelo micélio fúngico, formando uma barreira físicoquímica ao íon metal, e a processos metabólicos como precipitação extracelular, quelação, complexação e compartimentalização dos metais pesados (Cumming et al., 2001; Fomina et al., 2005; Bellion et al., 2006).

No que se refere à revegetação de áreas contaminadas, recomenda-se a utilização de plantas do gênero Eucalyptus devido a sua eficiência na absorção de nutrientes e produção de biomassa vegetal, as quais possuem elevada eficiência fotossintética (Mello et al., 2009), atuando como facilitadoras da regeneração florestal (Feyera et al., 2002; Neri et al., 2005). Segundo Bâ et al. (2010), o estabelecimento de essências florestais exóticas, como no caso do gênero Eucalyptus, somente é possível devido à associação das plantas com fECM capazes de proporcionar as condições necessárias para a manutenção das plantas no campo. Entretanto, para obter êxito na instalação de mudas de eucalipto micorrizadas em áreas contaminadas por metais, é necessário que estas apresentem crescimento satisfatório em casa de vegetação, possibilitando condições para que a colonização ocorra e permaneça após o transplante (Smith \& Read, 2008).

A inoculação de fECM em mudas utilizadas para revegetação de áreas contaminadas auxilia e acelera os processos de recuperação dos solos, ajudando no estabelecimento das mudas no campo e no restabelecimento da ciclagem de nutrientes (Angelini, 2008). Segundo estes autores, a inoculação ectomicorrízica influencia na sucessão vegetal, favorecendo o estabelecimento de espécies de plantas próprias de etapas sucessionais e resultando na recuperação da cobertura vegetal.

No setor florestal, resultados de pesquisa indicam que os metabólitos secundários ou óleos essenciais bioativos de algumas plantas podem ser utilizados como agentes biológicos no estímulo de crescimento de fungos simbiontes de interesse comercial (Zhi-Lin et al., 2007; Ludley et al., 2009) e como indutores biológicos do crescimento vegetal (Steffen et al., 2010). No entanto, os resultados existentes são escassos, sendo necessários mais estudos com relação aos benefícios inerentes da utilização de óleos essenciais de plantas bioativas na micorrização e crescimento de essências florestais, como o eucalipto, em solos contaminados.

Desse modo, este trabalho teve por objetivo determinar a melhor forma de aplicação do óleo essencial de eucalipto na formação de mudas de Eucalyptus grandis micorrizadas e sua influência no crescimento dessas mudas em solo contaminado por cobre.

\section{Material e métodos}

O experimento foi realizado em duas etapas. Primeiro, avaliou-se o efeito de diferentes formas de aplicação do óleo essencial de eucalipto na formação de mudas de Eucalyptus grandis em casa de vegetação. Posteriormente, as mudas foram transplantadas para solo naturalmente contaminado por cobre, coletado na área de rejeito de uma antiga mineradora de cobre, para avaliar o crescimento das plantas nestas condições. Utilizouse o delineamento inteiramente casualizado, com 10 
repetições para a avaliação da forma de utilização do óleo essencial na formação de mudas, e 20 repetições para a avaliação do efeito dos tratamentos na sobrevivência e no crescimento das mudas em solo contaminado por cobre.

\section{Obtenção do óleo essencial de eucalipto}

A extração do óleo essencial das folhas frescas de eucalipto foi realizada através da técnica de hidrodestilação (Serafini \& Cassel, 2001). Inicialmente, foram coletadas folhas de eucalipto, segundo a metodologia proposta por Vitti \& Brito (2003). Estas foram cortadas em pedaços de $2 \mathrm{~cm}$, pesadas e separadas em lotes individuais de $100 \mathrm{~g}$. Posteriormente, as folhas foram colocadas em balão volumétrico no aparelho de Clevenger modificado (Serafini \& Cassel, 2001), mantendo-se água destilada em ebulição dentro do balão com aquecedor externo. Os componentes vegetais líquidos extraídos, após a passagem por um condensador, foram coletados e mantidos sob refrigeração a $4{ }^{\circ} \mathrm{C}$ até sua utilização.

\section{Sementes}

As sementes de E. grandis foram obtidas na Estação Experimental de Silvicultura de Santa Maria (Fepagro). Após a assepsia das sementes em hipoclorito de sódio (Bonnassis, 2007), estas foram pré-germinadas em placas de Petri contendo meio de germinação de ácido bórico $(3 \mu \mathrm{M})$, glicose $\left(2 \mathrm{~g} \mathrm{~L}^{-1}\right)$, sulfato de cálcio $(500 \mu \mathrm{M})$ e ágar $\left(4 \mathrm{~g} \mathrm{~L}^{-1}\right)$, a $\mathrm{pH} 5,7$.

\section{Isolado ectomicorrízico}

Utilizou-se o fungo ectomicorrízico Pisolithus microcarpus, isolado UFSC Pt116, fornecido pelo banco de
fECM da Universidade Federal de Santa Catarina (UFSC), o qual foi mantido em meio de cultura sólido Melin Norkrans modificado - MNM (Marx, 1969) em pH 5,8.

Para produção do inoculante vegetativo do fECM, foram utilizadas duas formas de multiplicação do isolado. $\mathrm{Na}$ primeira, o isolado foi multiplicado utilizando-se adaptação da técnica descrita por Chávez et al. (2009), sendo realizadas suspensões micelianas do isolado ectomicorrízico, em $50 \mathrm{~mL}$ de meio MNM líquido (Marx, 1969) em Erlenmeyers de $150 \mathrm{~mL}$, a partir de discos de $10 \mathrm{~mm}$ de diâmetro obtidos das culturas em placa, seguindo-se de incubação a $26^{\circ} \mathrm{C}$, durante 30 dias. Para a segunda forma de multiplicação, o isolado ectomicorrízico foi multiplicado segundo a metodologia descrita acima, porém, adicionando-se $20 \mu \mathrm{L} \mathrm{L}^{-1}$ do óleo essencial de $E$. grandis ao meio de cultura líquido no momento da incubação.

Após o período de incubação, o conteúdo dos erlenmeyers, referentes a ambos os métodos de crescimento miceliano, foi fragmentado em $200 \mathrm{~mL}$ de meio MNM líquido, em liquidificador, durante 10 segundos. Em seguida, foi misturado a $300 \mathrm{~mL}$ de turfa estéril, em bequer de $1.000 \mathrm{~mL}$. Após a fragmentação do micélio fúngico e sua homogeneização no substrato, este foi acondicionado em incubadora a $26{ }^{\circ} \mathrm{C}$, até o momento da utilização.

\section{Tratamentos}

Para avaliação do efeito da forma de utilização do óleo essencial de eucalipto sobre a inoculação ectomicorrízica de mudas de eucalipto, formularam-se seis tratamentos (Tabela 1).

Tabela 1. Descrição dos tratamentos utilizados para avaliação do efeito da forma de utilização do óleo essencial de eucalipto sobre a inoculação ectomicorrízica de mudas de eucalipto.

\begin{tabular}{lcc}
\hline Tratamento & Inoculação do fECM em meio de cultura líquido & $\begin{array}{c}\text { Óleo essencial no substrato } \\
\left(\mu \mathrm{L}^{-1}\right)\end{array}$ \\
\hline Controle & ausente & 0 \\
$40 \mu \mathrm{L} \mathrm{L}-1$ & ausente & 40 \\
UFSC Pt 116 & presente & 0 \\
UFSC Pt $116+40 \mu \mathrm{L} \mathrm{L}^{-1}$ & presente & 40 \\
UFSC Pt $116\left(20 \mu \mathrm{L} \mathrm{L}^{-1}\right)$ & presente, com meio de cultura acrescido de óleo & 0 \\
UFSC Pt $116\left(20 \mu \mathrm{L} \mathrm{L}^{-1}\right)+40 \mu \mathrm{L} \mathrm{L}^{-1}$ & presente, com meio de cultura acrescido de óleo \\
essencial na concentração de $20 \mu \mathrm{L} \mathrm{L}^{-1}$ & 40 \\
\hline
\end{tabular}




\section{Preparo dos tubetes e produção das mudas de E. grandis}

Tubetes cônicos de PVC de $100 \mathrm{~cm}^{3}$ foram dispostos sobre telado, em casa de vegetação, e preenchidos $90 \%$ do seu volume com substrato fornecido pela empresa Turfa Fértil S.A. O substrato apresentou as seguintes características: $\mathrm{pH}$ em água $=5,8$; cálcio $=25,9 \mathrm{cmol}_{\mathrm{c}} \mathrm{dm}^{-3}$; magnésio $=4,7 \mathrm{cmol}_{\mathrm{c}} \mathrm{dm}^{-3} ; \mathrm{H}+\mathrm{Al}=2,5 \mathrm{cmol}_{\mathrm{c}} \mathrm{dm}^{-3} ; \mathrm{CTC}$ efetiva $=31,1 \mathrm{cmol}_{\mathrm{c}} \mathrm{dm}^{-3}$; matéria orgânica $=12 \%$; argila $=9 \%$; potássio $=176 \mathrm{mg} \mathrm{dm}^{-3} \mathrm{e}$ fósforo $=11,3 \mathrm{mg} \mathrm{dm}^{-3}$.

Após o preenchimento de $90 \%$ do volume dos tubetes com turfa, estes foram irrigados a fim de adensar o substrato no seu interior, chegando a um volume aproximado de $80 \%$ do tubete. Após este processo, completou-se o restante do volume dos tubetes com o substrato inoculado e não inoculado com fECM, mantendo-o úmido até o momento do transplante das plântulas de eucalipto.

Após o transplante, os tubetes permaneceram em casa de vegetação, sobre estrutura metálica para suporte de tubetes, comumente utilizado para mudas florestais. A reposição da umidade foi realizada adicionando-se diariamente água destilada aos tubetes, sendo aplicada solução nutritiva de Hoagland \& Arnon (1950), em intervalos de 20 dias.

Para a aplicação do óleo essencial de eucalipto nos tratamentos correspondentes, este foi solubilizado em etanol 96,5\% na proporção de 1:1 $\left(\mathrm{v} \mathrm{v}^{-1}\right)$, conforme metodologia proposta por Fabrowski et al. (2003). Foram aplicados $4 \mathrm{~mL}$ da solução contendo óleo essencial na concentração de $40 \mu \mathrm{L} \mathrm{L}^{-1}$ no substrato no entorno das mudas, em intervalos de 7 dias a contar da data de transplante das mudas.

\section{Avaliações}

Aos 90 dias após o transplante, foram determinadas e analisadas as variáveis: altura da muda $(\mathrm{cm})$, diâmetro do colo $(\mathrm{mm})$, massa da parte aérea fresca e seca $(\mathrm{mg})$, volume radicular $\left(\mathrm{cm}^{3}\right)$, massa das raízes secas $(\mathrm{mg})$, porcentual de colonização ectomicorrízica (\%) e o incremento no crescimento vegetal de cada tratamento em relação ao tratamento controle (\%).

Para a determinação da massa da parte aérea fresca e seca, as plantas foram cortadas no nível do substrato. Em seguida, foi pesada a parte aérea, caracterizando a massa da parte aérea fresca. As raízes foram separadas do substrato, lavadas com água destilada e determinado o diâmetro do colo com auxílio de paquímetro universal.
O volume radicular foi determinado através da densidade em água destilada. Para a determinação da porcentagem de colonização radicular, empregou-se a técnica das intersecções de Giovanetti \& Mosse (1980), modificado por Brundrett (1996).

Após, as raízes e a parte aérea das plantas foram colocadas em sacos de papel individuais devidamente identificados e levados à estufa a $65{ }^{\circ} \mathrm{C}$, onde permaneceram até atingir peso constante, efetuando-se a determinação da massa da parte aérea seca e a massa de raízes secas.

Para a determinação do incremento no crescimento vegetal, adaptou-se a metodologia apresentada por Ying Chu et al. (2001), utilizando-se a equação: [(massa seca da planta inteira no tratamento y - massa seca da planta inteira no tratamento controle) / massa seca da planta inteira no tratamento $\mathrm{y}]^{*} 100$, onde o tratamento "y" correspondeu ao tratamento avaliado em relação ao tratamento controle.

Os dados obtidos nas variáveis foram submetidos à análise de variância e comparação de médias pelo teste de Tukey a $5 \%$ de probabilidade de erro pelo software Sisvar (Ferreira, 2000), tomando-se como base os níveis de significância maiores que $95 \%(\mathrm{P} \leq 0,05)$.

\section{Avaliação em campo da utilização do óleo essencial de eucalipto no crescimento de plantas de $E$. grandis micorrizadas em solo contaminado por cobre}

Foi avaliado o crescimento das mudas de $E$. grandis em solo contaminado com cobre em condições de casa de vegetação. Posteriormente, as mudas foram transplantadas para o campo, na área de rejeito das Minas do Camaquã, pertencente à Companhia Brasileira do Cobre (CBC), localizada no Município de Caçapava do Sul, RS, a fim de determinar a sobrevivência e o crescimento em condições naturais de solo contaminado.

\section{Coleta do solo contaminado por cobre}

O solo utilizado no experimento foi coletado na área de rejeito das Minas do Camaquã. O solo foi coletado na profundidade de $0-20 \mathrm{~cm}$ e acondicionado em sacos plásticos até o momento da utilização.

O solo apresentou as seguintes características físicoquímicas: $27 \%$ de argila; $\mathrm{pH}$ em água $=6,8$; cálcio $=$ $3,3 \mathrm{cmol}_{\mathrm{c}} \mathrm{dm}^{-3} ;$ magnésio $=0,4 \mathrm{cmol}_{\mathrm{c}} \mathrm{dm}^{-3} ; \mathrm{H}+\mathrm{Al}=0,6$ $\mathrm{cmol} \mathrm{dm}_{\mathrm{c}}$; CTC efetiva $=3,8 ; \mathrm{CTC} \mathrm{pH} \mathrm{7}=4,4 \mathrm{cmol}_{\mathrm{c}} \mathrm{dm}^{-3}$; matéria orgânica $=0,3 \%$; potássio $=28 \mathrm{mg} \mathrm{dm}^{-3}$; fósforo $=142,3 \mathrm{mg} \mathrm{dm}^{-3}$; manganês $=10,3 \mathrm{mg} \mathrm{dm}^{-3} \mathrm{e}$ cobre $=$ $286,3 \mathrm{mg} \mathrm{dm}^{-3}$. 


\section{Instalação dos experimentos em casa de vegetação e a campo}

Decorrido o período de 90 dias de crescimento das mudas nos tubetes, estas foram transplantadas para vasos de $10 \mathrm{~L}$, contendo $8 \mathrm{~L}$ do solo naturalmente contaminado por cobre. No momento do transplante, as mudas foram retiradas dos tubetes e inseridas em uma cova no centro de cada vaso. Após o transplante, os vasos permaneceram em casa de vegetação por 150 dias, sendo irrigados diariamente com água destilada.

Após o período de 150 dias de crescimento nos vasos, as plantas foram transplantadas para área de rejeito das Minas do Camaquã. No momento do transplante, as plantas foram retiradas dos vasos e inseridas em uma cova, sem a adição de fertilizantes e corretivos. As plantas permaneceram no campo por 240 dias, não sendo efetuados tratos culturais, a fim de determinar a sobrevivência nas condições naturais do ambiente.

\section{Avaliações}

Em casa de vegetação, avaliaram-se teores de cobre no tecido vegetal, altura e diâmetro do colo das plantas. A altura foi determinada com régua milimetrada, sendo obtida pela distância do colo da planta até a extremidade das últimas axilas foliares, e o diâmetro do colo obtido com auxílio de paquímetro, sendo realizadas aos 30,60, 90, 120 e 150 dias após o transplante das mudas. Para a determinação do teor de cobre, efetuou-se a digestão nítrico-perclórica do tecido vegetal e determinação em espectrofotometria de absorção atômica, conforme metodologia descrita por Lawrense (1999).
No campo foram avaliadas a altura das plantas, diâmetro do colo e porcentual de sobrevivência. A altura e diâmetro do coleto foram determinadas conforme descrição anterior.

Os dados de altura das mudas, diâmetro do colo e teor de cobre nas folhas foram submetidos à análise de variância e as médias comparadas pelo teste de Tukey a $5 \%$ de probabilidade de erro pelo software Sisvar (Ferreira, 2000), tomando-se como base os níveis de significância maiores que $95 \%(\mathrm{P} \leq 0,05)$.

\section{Resultados e discussão}

\section{Óleo essencial de eucalipto na formação de mudas de $E$. grandis micorrizadas}

As mudas de eucalipto inoculadas com o fECM P. microcarpus (UFSC Pt 116) que receberam o óleo essencial de eucalipto, tanto na formação do inóculo ectomicorrízico (tratamento UFSC Pt $116\left(20 \mu \mathrm{L} \mathrm{L}^{-1}\right)$ ) como na aplicação direta no substrato (tratamento UFSC Pt $116+40 \mu \mathrm{L} \mathrm{L}^{-1}$ ), apresentaram altura, diâmetro do colo, massa fresca e seca da parte aérea significativamente superior aos demais tratamentos (Tabela 2). Resultados demonstrando o efeito positivo da associação ectomicorrízica no crescimento das plantas têm sido relatados na literatura (Andreazza et al., 2004; Mello et al., 2009).

Tabela 2. Altura, diâmetro do colo e massa fresca e seca da parte aérea de mudas de Eucalyptus grandis submetidas a diferentes formas de inoculação, 90 dias após o transplante para os substratos.

\begin{tabular}{lcccc}
\hline \multicolumn{1}{c}{ Tratamento } & $\begin{array}{c}\text { Altura das } \\
\text { mudas } \\
(\mathbf{c m})\end{array}$ & $\begin{array}{c}\text { Diâmetro do } \\
\text { colo } \\
(\mathbf{m m})\end{array}$ & $\begin{array}{c}\text { Massa fresca da } \\
\text { parte aérea } \\
(\mathbf{m g})\end{array}$ & $\begin{array}{c}\text { Massa seca da } \\
\text { parte aérea } \\
(\mathbf{m g})\end{array}$ \\
\hline Controle & $16,25 \mathrm{~d}$ & $1,68 \mathrm{c}$ & $1020 \mathrm{~d}$ & $234 \mathrm{~d}$ \\
Controle $+40 \mu \mathrm{L} \mathrm{L}^{-1}$ & $17,46 \mathrm{~d}$ & $1,70 \mathrm{c}$ & $1150 \mathrm{~d}$ & $385 \mathrm{~d}$ \\
UFSC Pt 116 & $23,93 \mathrm{~b}$ & $2,45 \mathrm{~b}$ & $2400 \mathrm{~b}$ & $702 \mathrm{~b}$ \\
UFSC Pt $116+40 \mu \mathrm{L} \mathrm{L}^{-1}$ & $28,21 \mathrm{a}$ & $2,87 \mathrm{a}$ & $3030 \mathrm{a}$ & $949 \mathrm{a}$ \\
UFSC Pt $116\left(20 \mu \mathrm{L} \mathrm{L}^{-1}\right)$ & $26,88 \mathrm{a}$ & $2,79 \mathrm{a}$ & $2890 \mathrm{a}$ & $904 \mathrm{a}$ \\
UFSC Pt $116\left(20 \mu \mathrm{LL}^{-1}\right)+40 \mu \mathrm{LL} \mathrm{L}^{-1}$ & $21,25 \mathrm{c}$ & $2,44 \mathrm{~b}$ & $1870 \mathrm{c}$ & $598 \mathrm{c}$ \\
\hline CV $(\%)^{*}$ & 7,74 & 6,01 & 6,69 & 8,65 \\
\hline
\end{tabular}

Médias seguidas pela mesma letra minúscula na coluna não diferem entre si pelo teste de Tukey a $5 \%$ de probabilidade.; *Coeficiente de variação. Média de dez repetições $(n=10)$. 
Além dos benefícios que os fECM proporcionam às plantas, devido ao aumento na absorção de água $\mathrm{e}$ nutrientes, poderá haver a produção de fitormônios (ácido indol acético - AIA e auxinas) em resposta à exsudação de compostos fenólicos pelas raízes da planta no momento da infecção (Smith \& Read, 2008). Estes fitormônios são excretados na micorrizosfera, ficando biodisponíveis para as plantas e apresentando efeito importante no crescimento vegetal.

Embora a adição do óleo essencial tenha proporcionado aumento nos parâmetros altura, diâmetro do colo, massa fresca e seca da parte aérea das mudas, quando aplicado no tratamento onde o inóculo do fECM já havia recebido a adição do óleo essencial (UFSC Pt $116\left(20 \mu \mathrm{L} \mathrm{L}^{-1}\right)+$ $40 \mu \mathrm{L} \mathrm{L}^{-1}$ ), observou-se crescimento inferior das mudas em relação aos tratamentos onde o óleo essencial foi utilizado somente no inóculo ou em aplicações posteriores no substrato. Possivelmente, este resultado esteja relacionado à sobreposição da aplicação, o que pode ter prejudicado o crescimento das mudas em função da concentração elevada do óleo essencial de eucalipto. Segundo Souza (2003), a massa seca de ramos e folhas é o parâmetro mais importante em estudos onde se busca verificar a eficiência de determinadas variáveis sobre o desenvolvimento e crescimento vegetal. Os resultados desse trabalho evidenciam eficiência do óleo essencial no estímulo ao desenvolvimento de mudas em condições de casa de vegetação.

De acordo com Barker et al. (1998), os fECM podem também produzir hormônios que diminuem o crescimento das raízes e podem induzir à bifurcação das pontas e à formação de aglomerados de raízes, variando as estruturas conforme a espécie hospedeira e o fungo associado. No entanto, o efeito de diminuição do crescimento radicular não foi observado no presente trabalho, onde plantas colonizadas com o fungo P. microcarpus (UFSC PT 116) apresentaram valores de massa seca de raízes e volume radicular significativamente superior aos observados nas plantas que não formaram associação ectomicorrízica (Tabela 3).

Tabela 3. Massa seca de raízes e volume radicular de mudas de Eucalyptus grandis submetidas a diferentes formas de inoculação ectomicorrízica, 90 dias após o transplante para os substratos.

\begin{tabular}{lcc}
\hline \multicolumn{1}{c}{ Tratamento } & $\begin{array}{c}\text { Massa seca de raízes } \\
(\mathbf{m g})\end{array}$ & $\begin{array}{c}\text { Volume radicular } \\
\left(\mathbf{c m}^{3}\right)\end{array}$ \\
\hline Controle & $101 \mathrm{c}$ & $0,864 \mathrm{~d}$ \\
Controle $+40 \mu \mathrm{L} \mathrm{L}^{-1}$ & $131 \mathrm{c}$ & $1,012 \mathrm{~d}$ \\
$\mathrm{UFSC}$ Pt 116 & $168 \mathrm{~b}$ & $1,170 \mathrm{bc}$ \\
$\mathrm{UFSC}$ Pt $116+40 \mu \mathrm{L} \mathrm{L}^{-1}$ & $241 \mathrm{a}$ & $1,435 \mathrm{a}$ \\
$\mathrm{UFSC}$ Pt $116\left(20 \mu \mathrm{L} \mathrm{L}^{-1}\right)$ & $211 \mathrm{a}$ & $1,325 \mathrm{a}$ \\
$\mathrm{UFSC}$ Pt $116\left(20 \mu \mathrm{L} \mathrm{L}^{-1}\right)+40 \mu \mathrm{L} \mathrm{L}^{-1}$ & $161 \mathrm{~b}$ & $1,102 \mathrm{c}$ \\
\hline CV $(\%) *$ & 8,13 & 9,30 \\
\hline Médias seguidas pela mesma letra minúscula na coluna não diferem entre si pelo teste de Tukey a $5 \%$ de \\
probabilidade; *Coeficiente de variação. Média de dez repetições $(\mathrm{n}=10)$.
\end{tabular}

Observou-se que a utilização do óleo essencial de eucalipto, tanto no momento da produção do inóculo (UFSC PT 116 - $20 \mu \mathrm{L} \mathrm{L}^{-1}$ ) como via aplicações posteriores no substrato (UFSC Pt $116-40 \mu \mathrm{L} \mathrm{L}^{-1}$ ), estimulou significativamente a porcentagem de colonização ectomicorrízica (Figura 1). Esse resultado pode estar associado aos sinais bioquímicos responsáveis pela simbiose fungo-planta.

Dessa maneira, a presença do óleo essencial estaria atuando de forma efetiva no quimiotropismo entre as hifas fúngicas e as células radiculares. Segundo Wong \& Fortin (1990) e Weiss et al. (1997), os sinais bioquímicos de reconhecimento compõem a produção e o acúmulo de fenilpropanóides nas raízes, bem como a liberação pelo fungo de compostos indólicos que atuam na rizogênese, induzindo a adesão das hifas fúngicas, passo inicial para formação de ectomicorriza. Entretanto, a aplicação do óleo essencial de eucalipto nas mudas onde o inóculo ectomicorrízico já continha o óleo essencial (UFSC Pt 16 $\left.\left(20 \mu \mathrm{L} \mathrm{L}^{-1}\right)+40 \mu \mathrm{L} \mathrm{L}^{-1}\right)$ resultou em plantas com menor colonização radicular (Figura 1) e significativamente menores em relação às plantas dos tratamentos que receberam o óleo essencial na inoculação ou durante a formação das mudas (Tabelas 2 e 3 ). 
A aplicação do óleo essencial de eucalipto sobre o substrato resultou em plantas com crescimento $35 \%$ superior ao tratamento controle (Figura 2). Observouse também que a inoculação das mudas com o fECM P. microcarpus, sem a adição do óleo essencial, proporcionou crescimento das plantas $59,6 \%$ superior ao observado nas plantas do tratamento controle (Figura 2). Esses dados corroboram com Diniz (2007), onde descreve que a simbiose não só aumenta a biomassa vegetal, como também influencia a proporção na qual esta se distribui entre a parte aérea e a raiz das plantas.

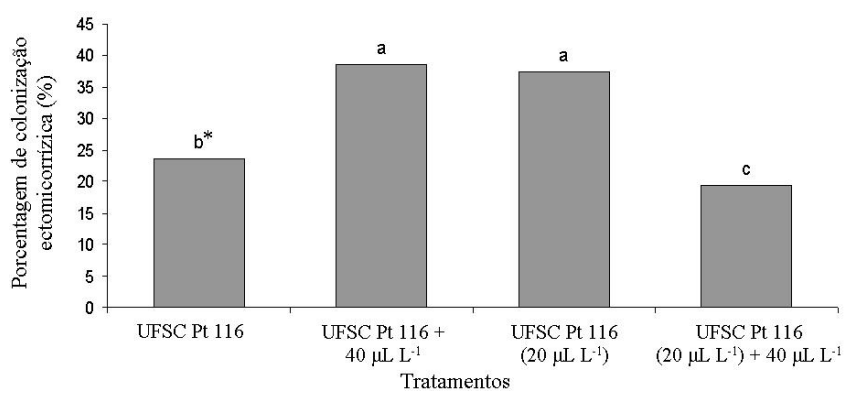

Figura 1. Incremento no crescimento vegetal (\%) proporcionado pelos tratamentos em relação ao tratamento controle nas mudas de Eucalyptus grandis aos 90 dias após o transplante para os substratos. * Médias seguidas pela mesma letra não diferem entre si pelo teste de Tukey a $5 \%$ de probabilidade. $\mathrm{CV}=9,17 \%$.

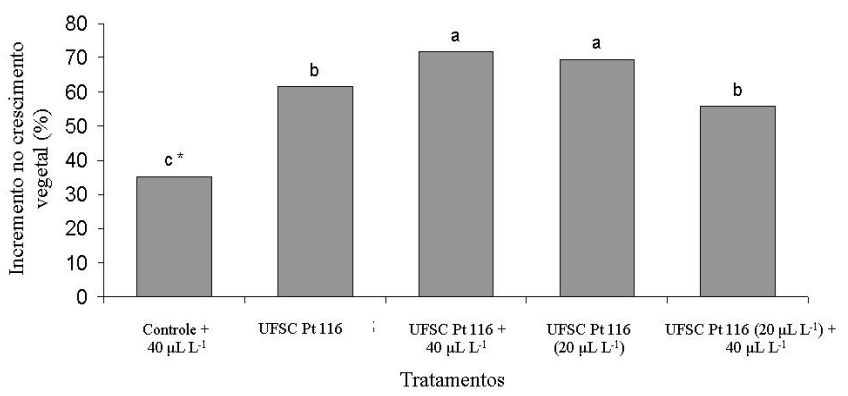

Figura 2. Porcentagem de colonização ectomicorrízica das raízes de Eucalyptus grandis aos 90 dias após o transplante para substratos com diferentes formas de inoculação. *Médias seguidas pela mesma letra não diferem entre si pelo teste de Tukey a $5 \%$ de probabilidade. $\mathrm{CV}=7,25 \%$.

Entretanto, quando as mudas foram inoculadas com o fECM e submetidas à utilização do óleo essencial de eucalipto, o incremento no crescimento vegetal foi de $71 \%$ e $68,7 \%$, respectivamente, para os tratamentos onde a utilização do óleo essencial ocorreu via inoculação e via aplicações posteriores no substrato. Quando da aplicação do óleo essencial de eucalipto nas mudas onde o inóculo ectomicorrízico já continha o óleo essencial (UFSC Pt $\left.16\left(20 \mu \mathrm{L} \mathrm{L}^{-1}\right)+40 \mu \mathrm{L} \mathrm{L}^{-1}\right)$, observou-se incremento de $57 \%$ no crescimento vegetal. 
Crescimento de plantas de $E$. grandis micorrizadas em solo contaminado por cobre

Quando as mudas foram transplantadas para o solo contendo elevado teor de cobre, o crescimento foi semelhante ao evidenciado durante a formação das mudas em condição de casa de vegetação, ou seja, as plantas inoculadas com o fECM e que receberam o óleo essencial continuaram apresentando crescimento significativamente maior em relação aos demais tratamentos (Tabela 4).

Tabela 4. Altura das mudas e diâmetro do colo de Eucalyptus grandis aos 30, 60, 90, 120 e 150 dias após o transplante para o solo contaminado com cobre, em condições de casa de vegetação.

\begin{tabular}{|c|c|c|c|c|c|}
\hline \multirow{2}{*}{ Tratamento } & \multicolumn{5}{|c|}{ Altura das mudas (cm) } \\
\hline & 30 dias & 60 dias & 90 dias & 120 dias & 150 dias \\
\hline Controle & $14,66 \mathrm{~d}$ & $29,91 \mathrm{~d}$ & $45,16 \mathrm{c}$ & $55,33 \mathrm{c}$ & $58,33 \mathrm{c}$ \\
\hline Controle $+40 \mu \mathrm{L} \mathrm{L}^{-1}$ & $17,33 \mathrm{~d}$ & $34,91 \mathrm{~cd}$ & $47,00 \mathrm{c}$ & $60,66 \mathrm{~b}$ & $64,25 \mathrm{~b}$ \\
\hline UFSC Pt 116 & $24,41 \mathrm{~b}$ & $38,41 \mathrm{bc}$ & $48,91 \mathrm{~b}$ & $63,83 \mathrm{~b}$ & $67,58 \mathrm{~b}$ \\
\hline UFSC Pt $116+40 \mu \mathrm{L} \mathrm{L}^{-1}$ & $28,05 \mathrm{ab}$ & $42,83 \mathrm{ab}$ & $49,91 \mathrm{~b}$ & $66,50 \mathrm{a}$ & $71,83 \mathrm{a}$ \\
\hline UFSC Pt $116\left(20 \mu \mathrm{L} \mathrm{L}^{-1}\right)$ & 30,83 a & 45,83 a & 54,75 a & 65,83 a & $69,16 \mathrm{a}$ \\
\hline UFSC Pt $116\left(20 \mu \mathrm{L} \mathrm{L}^{-1}\right)+40 \mu \mathrm{L} \mathrm{L}^{-1}$ & $22,41 \mathrm{c}$ & $38,75 \mathrm{bc}$ & $52,50 \mathrm{ab}$ & $57,83 \mathrm{c}$ & $66,55 \mathrm{~b}$ \\
\hline $\mathrm{CV}(\%)^{* *}$ & 9,38 & 8,00 & 8,66 & 9,26 & 8,58 \\
\hline \multirow{2}{*}{ Tratamento } & \multicolumn{5}{|c|}{ Diâmetro do colo (mm) } \\
\hline & 30 dias & 60 dias & 90 dias & 120 dias & 150 dias \\
\hline Controle & $1,13 \mathrm{~d}$ & $1,65 \mathrm{c}$ & $2,21 \mathrm{c}$ & $4,71 \mathrm{c}$ & $6,60 \mathrm{c}$ \\
\hline Controle $+40 \mu \mathrm{L} \mathrm{L}^{-1}$ & $1,33 \mathrm{c}$ & $1,98 \mathrm{c}$ & $2,50 \mathrm{c}$ & $5,28 \mathrm{bc}$ & $7,60 \mathrm{~b}$ \\
\hline UFSC Pt 116 & $1,58 \mathrm{~b}$ & $2,20 \mathrm{~b}$ & $3,25 \mathrm{bc}$ & $5,85 \mathrm{~b}$ & $8,00 \mathrm{ab}$ \\
\hline UFSC Pt $116+40 \mu \mathrm{L} \mathrm{L}^{-1}$ & $1,75 \mathrm{a}$ & $2,46 \mathrm{a}$ & $3,68 \mathrm{~b}$ & $6,71 \mathrm{a}$ & $8,20 \mathrm{a}$ \\
\hline UFSC Pt $116\left(20 \mu \mathrm{L} \mathrm{L}^{-1}\right)$ & $1,72 \mathrm{a}$ & $2,57 \mathrm{a}$ & $3,73 \mathrm{a}$ & $6,42 \mathrm{a}$ & $8,20 \mathrm{a}$ \\
\hline UFSC Pt $116\left(20 \mu \mathrm{L} \mathrm{L}^{-1}\right)+40 \mu \mathrm{L} \mathrm{L}^{-1}$ & $1,57 \mathrm{~b}$ & $2,21 \mathrm{~b}$ & $3,18 \mathrm{bc}$ & $5,57 \mathrm{~b}$ & $7,60 \mathrm{~b}$ \\
\hline $\mathrm{CV}(\%)^{*}$ & 8,54 & 9,02 & 8,66 & 8,98 & 9,14 \\
\hline
\end{tabular}

Provavelmente, este resultado no crescimento esteja relacionado à maior colonização ectomicorrízica observada nestes tratamentos, a qual, devido aos benefícios da simbiose ectomicorrízica, proporciona melhores condições de crescimento na presença de metais no solo.

As plantas de eucalipto não inoculadas com o fECM $P$. microcarpus também apresentaram crescimento, embora limitado, no solo contaminado por cobre (Tabela 4). Isso pode ter ocorrido devido às plantas não micorrizadas, dependendo do estado fisiológico e nutricional, poderem se desenvolver, embora com dificuldade, em solos contaminados por metais pesados, o que é viabilizado por mecanismos de captação e efluxo de metais através da membrana plasmática, quelação de metais no citosol, ação de fitoquelatinas e compartimentalização dos metais no vacúolo (Hall, 2002).
O teor de cobre no tecido das plantas submetidas aos tratamentos onde houve a inoculação ectomicorrízica e a utilização do óleo essencial de eucalipto, foi significativamente inferior ao observado no tecido vegetal das plantas submetidas aos demais tratamentos (Figura 3). Fomina et al. (2005) demonstram que a presença do manto fúngico sobre as raízes da planta hospedeira não altera o deslocamento dos metais presentes na solução do solo até a superfície das raízes, mas impede sua translocação para o interior das plantas.

Provavelmente, o menor teor de cobre encontrado na parte aérea das plantas submetidas aos tratamentos onde houve inoculação micorrízica e presença do óleo essencial, tanto no inóculo utilizado como na adição posterior (tratamentos UFSC Pt $116\left(20 \mu \mathrm{L} \mathrm{L}^{-1}\right)$ e UFSC Pt $\left.116+40 \mu \mathrm{L} \mathrm{L}^{-1}\right)$ (Figura 3), tenha resultado em menor 
fitotoxidez de cobre, visto que, quanto menor o teor de cobre translocado, menor será a interferência deste na absorção e translocação de elementos como o fósforo, potássio, cálcio e magnésio, nutrientes essenciais ao desenvolvimento vegetal (Soares et al., 2000).

Figura 3. Teor de cobre nas folhas de Eucalyptus grandis

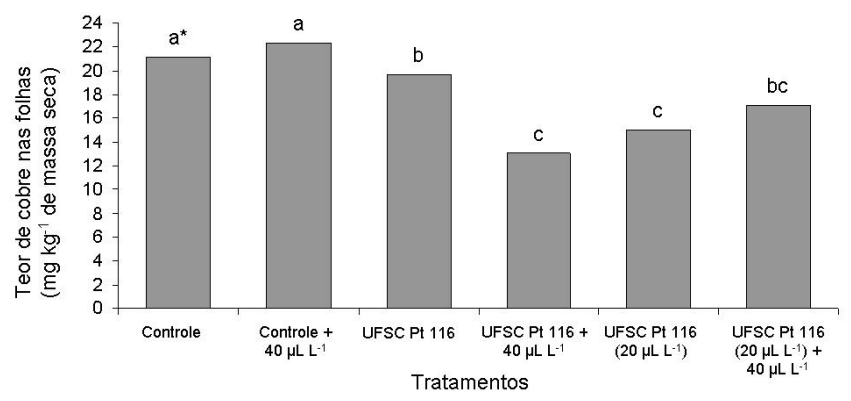

submetido aos diferentes tratamentos, 150 dias após o transplante para o solo contaminado. *Médias seguidas pela mesma letra não diferem entre si pelo teste de Tukey a $5 \%$ de probabilidade. $\mathrm{CV}=7,62$.

No campo, o efeito dos tratamentos de inoculação e óleo essencial ficou evidente devido à diferença observada quanto ao porcentual de sobrevivência das plantas (Tabela 5). Embora após o período de formação das mudas em casa de vegetação, as plantas não tenham recebido nenhum tipo de tratamento, a maior colonização ectomicorrízica (Figura 1) e o incremento no crescimento das mudas inerente aos tratamentos fECM + óleo (Figura 2) resultaram em plantas com condições de permanência no solo contaminado.
É importante observar que o solo presente nas Minas do Camaquã, RS, é oriundo do rejeito do processo de mineração do cobre, o qual, após a moagem da rocha e o processo físico-químico de extração do cobre, foi depositado sobre área de mineração, estando sujeito aos fatores climáticos e biológicos. Além disso, no momento do transplante do E. grandis para o campo, não foram adotadas tecnologias de amenização do efeito de metais pesados sobre o crescimento vegetal (Badora et al., 1998; Ge et al., 2000; Mulligan et al., 2001; Accioly et al., 2004; Accioly et al., 2009), sendo as diferenças observadas no crescimento das plantas no campo inerentes aos tratamentos utilizados no momento da produção das mudas em condição de casa de vegetação.

\section{Conclusões}

O óleo essencial de Eucalyptus grandis favorece o crescimento de mudas de eucalipto micorrizadas com o isolado UFSC Pt 116, quando aplicado diretamente no substrato durante o crescimento das mesmas em casa de vegetação.

As mudas de E. grandis que receberam aplicação do óleo essencial de eucalipto apresentam maior porcentagem de colonização micorrízica.

O óleo essencial de E. grandis aplicado em mudas de eucalipto micorrizadas favorece o crescimento e a sobrevivência das plantas em solo contaminado por cobre.

Tabela 5. Porcentagem de sobrevivência, altura e diâmetro do colo das plantas de Eucalyptus grandis aos 240 dias após o transplante para o solo contaminado com cobre em condições de campo.

\begin{tabular}{lccc}
\hline \multicolumn{1}{c}{ Tratamento } & $\begin{array}{c}\text { Sobrevivência } \\
(\mathbf{\%})\end{array}$ & $\begin{array}{c}\text { Altura das plantas } \\
(\mathbf{c m})\end{array}$ & $\begin{array}{c}\text { Diâmetro do colo } \\
(\mathbf{m m})\end{array}$ \\
\hline Controle & 15 & $63,45 \mathrm{~d} *$ & $7,60 \mathrm{~d}$ \\
Controle $+40 \mu \mathrm{L} \mathrm{L}^{-1}$ & 30 & $66,86 \mathrm{~d}$ & $8,57 \mathrm{~d}$ \\
UFSC Pt 116 & 45 & $73,44 \mathrm{bc}$ & $11,40 \mathrm{~b}$ \\
UFSC Pt $116+40 \mu \mathrm{L} \mathrm{L}^{-1}$ & 75 & $87,05 \mathrm{a}$ & $13,25 \mathrm{a}$ \\
UFSC Pt $116\left(20 \mu \mathrm{L} \mathrm{L}^{-1}\right)$ & 60 & $75,14 \mathrm{~b}$ & $11,85 \mathrm{~b}$ \\
UFSC Pt $116\left(20 \mu \mathrm{L} \mathrm{L}^{-1}\right)+40 \mu \mathrm{L} \mathrm{L}^{-1}$ & 40 & $70,09 \mathrm{c}$ & $10,00 \mathrm{~cd}$ \\
\hline $\mathrm{CV}(\%) * *$ & & 10,54 & 13,14 \\
\hline
\end{tabular}

* Médias seguidas pela mesma letra minúscula na coluna não diferem entre si pelo teste de Tukey a 5\% de probabilidade; ** Coeficiente de variação. 


\section{Referências}

ACCIOLY, A. M. A.; SIQUEIRA, J. O.; CURI, N.; MOREIRA, F. M. S. Amenização do calcário na toxidez de zinco e cádmio para mudas de Eucalyptus camaldulensis cultivadas em solo contaminado. Revista Brasileira de Ciência do Solo, Viçosa, MG, v. 28, n. 4, p. 775-783, 2004.

ACCIOLY, A. M. A.; SOARES, S. C. R. F.; SIQUEIRA, J. O. Silicato de cálcio como amenizante da toxidez de metais pesados em mudas de eucalipto. Pesquisa Agropecuária Brasileira, Brasília, DF, v. 44, n. 2, p. 180-188, 2009.

AMEZCUA-ALLIERI, M. A.; LEAD, J. R.; RODRÍGUEZVÁZQUEZ, R. Impact of microbial activity on copper, lead and nickel mobilization during the bioremediation of soil PAHs. Chemosphere, Atlanta, v. 61, n. 4, p. 484-491, 2005.

ANDREAZZA, R.; ANTONIOLLI, Z. I.; SILVA, R. F. da. LONGHI, S. J. Espécies de Pisolitus sp. na produção de mudas de Eucalyptus grandis Hill ex Maiden em solo arenoso. Ciência Florestal, Santa Maria, RS, v. 14, n. 2, p. 51-59, 2004.

ANGELINI, G. A. R. Seleção de fungos micorrízicos arbusculares e ectomicorrízicos para simbioses eficientes com leguminosas arbóreas do gênero Acácia. 2008. 93 f. Dissertação (Mestrado em Agronomia) - Universidade Federal Rural do Rio de Janeiro, Rio de Janeiro.

BÂ, A. M.; DIÉDHIOU, A. G.; PRIN, Y.; GALIANA, A. Management of ectomycorrhizal symbionts associated to useful exotic tree species to improve reforestation performances in tropical Africa. Annals of Forest Science, Champenoux, v. 67, n. 3, p. 298-307, 2010.

BADORA, A.; FURRER, G.; GRÜNWALD, A.; SCHULIN, $\mathrm{R}$. Immobilization of zinc and cadmium in polluted soils by polynuclear $\mathrm{Al}_{13}$ and $\mathrm{Al}$-Montmorillonite. Soil and Sediment Contamination: An International Journal, Michigan, v. 7, n. 5, p. 573-588, 1998.

BARKER, S. J.; TAGU, D.; DELP, G. Regulation of root and fungal morphogenesis in mycorrhizal symbioses. Plant Physiology, Urbana, v. 116, n. 4, p. 1201-1207, 1998.

BELLION, M.; COURBOT, M.; JACOB, C.; BLAUDEZ, D.; CHALOT, M. Extracellular and cellular mechanisms sustaining metal tolerance in ectomycorrhizal fungi. FEMS Microbiology Letters, Birmingham, v. 254, n. 2, p. 173-181, Jan. 2006.

BONNASSIS, P. A. P. Caracterização de isolados fúngicos ectomicorrízicos na promoção do crescimento e na colonização radicular de Eucalyptus dunnii Maiden. 2007. 69 f. Dissertação (Mestrado em Biotecnologia) - Universidade Federal de Santa Catarina, Florianópolis.

BRUNDRETT, M. Working with mycorrhizas in forestry and agriculture. Canberra: ACIAR, 1996. 374 p.

CAMARGO, O. A.; ALLEONI, L. R. F.; CASAGRANDE, J. C. Reações dos micronutrientes e elementos tóxicos no solo. In: FERREIRA, M. E.; CRUZ, M. C. P.; VAN RAIJ, B. ABREU, C. A. (Eds.). Micronutrientes e elementos tóxicos na agricultura. Jaboticabal: CNPq/FAPESP/POTATOS. 2001. p. 89-177.
CHÁVEZ, D. M.; PEREIRA, G. C.; MACHUCA, Á. H. Efecto de tipos de inóculos de tres especies fúngicas en la micorrización controlada de plántulas de Pinus radiata. Bosque, Valdivia, v. 30, n. 1, p. 4-9, enero/abril 2009.

CUMMING, J. R.; SWIGER, T. D.; KURNIK, B. S.; PANACCIONE, D. G. Organic acid exudation by Laccaria bicolor and Pisolithus tinctorius exposed to aluminum in vitro. Canadian Journal of Forest Research, Ottawa, v. 31, n. 4, p. 703-710, Apr. 2001.

DINIZ, P. F. A. Influência do fungo micorrízico arbuscular (Glomus clarum) sobre características biofísicas, nutricionais, metabólicas e anatômicas em plantas jovens de seringueira. 2007. 112 f. Dissertação (Mestrado em Ciências) - Universidade Federal de Lavras, Lavras, MG.

FABROWSKI, F. J.; MUÑIZ, G. I. B. de; NAKASHIMA, T.; NISGOSKI, S.; KLOCH, U. Investigação da presença de óleo essencial em Eucalyptus smithii R. T. Baker por meio da anatomia de seu lenho e casca. Ciência Florestal, Santa Maria, RS, v. 13, n. 1, p. 95-106, 2003.

FERREIRA, D. F. Sistemas de análise estatística para dados balanceados. Lavras, MG: UFLA/DEX/SISVAR, 2000. 145 p.

FEYERA, S.; BECK, E.; LÜTTGE, U. Exotic trees as nurse-trees for the regeneration of natural tropical forests. Trees: Structure and Function, Darmstadt, v. 16, n. 4-5, p. 245-249, 2002.

FOMINA, M.; HILLIER, S.; CHARNOCK, J. M.; MELVILLE, K.; ALEXANDER, I. J.; GADD, G. M. Role of oxalic acid overexcretion in transformations of toxic metal minerals by Beauveria caledonica. Applied and Environmental Microbiology, Jena, v. 71, n. 1, p. 371-381, 2005.

GADD, G. M. Microbial influence on metal mobility and application for bioremediation. Geoderma, Tucson, v. 112, n. 2-4, p. 109-119, 2004.

GE, Y.; MURRAY, P.; HENDERSHOT, W. H. Trace metal speciation and bioavailability in urban soils. Environmental Pollution, Amherst, v. 107, n. 1, p. 137-144, 2000.

GIOVANETTI, M. G.; MOSSE, B. An evaluation of techniques for measuring vesicular-arbuscular mycorrhizal infection in roots. New Phytologist, Lancaster, v. 84, n. 3, p. 489-500, 1980.

GÖHRE, V.; PASZKOWSKI, U. Contribution of the arbuscular mycorrhizal symbiosis to heavy metal phytoremediation. Planta, Bonn, v. 223, n. 6, p. 1115-1122, 2006.

GRASSI FILHO, H. Cobre na planta. In: UNIVERSIDADE ESTADUAL PAULISTA. Faculdade de Ciências Agronômicas. Departamento de Recursos Naturais. Ciência do Solo. Botucatu, 2005. Disponível em: $<$ http://ciencialivre.pro.br/media/5d14138ca 192e610ffff81e2ffffd523.pdf>. Acesso em: 8 set. 2009.

GRAZZIOTTI, P. H.; SIQUEIRA, J. O.; MOREIRA, F. M. S. Espécies arbóreas e ectomicorrizas em relação ao excesso de metais pesados. In: CURI, N.; MARQUES, J. J.; GUILHERME, L. R. G.; LIMA, J. M. de.; LOPES, A. S.; ALVAREZ, V. H. (Eds.). Tópicos em Ciência do Solo. Viçosa, MG: Sociedade Brasileira de Ciência do Solo, 2003. 430 p. v. 1. 
HALL, J. L. Cellular mechanisms for heavy metal detoxification and tolerance. Journal of Experimental Botany, Lancaster, v. 53, n. 366 , p. 1-11, 2002.

HOAGLAND, D. R.; ARNON, D. I. The water culture method for growing plants without soil. Berkeley, CA: University of California, 1950. 347 p. (California Agricultural Experiment Station. Circular, 347).

KHAN, A. G. Mycorrhizoremediation: an enhanced form of phytoremediation. Journal of Zhejiang University Science, Zhejiang, v. 7, n. 7, p. 503-514, 2006.

LAWRENSE, H. K. Sampling and analysis methods. New York: Lewis Publisheres, 1999. 1697 p.

LUDLEY, K. E.; ROBINSON, C. H.; JICKELLS, S.; CHAMBERLAIN, P. M.; WHITAKER, J. Potential for monoterpenes to affect ectomycorrhizal and saprotrophic fungal activity in coniferous forest is revealed by novel experimental system. Soil Biology \& Biochemistry, Brisbane, v. 41, n. 1, p. 117-124, 2009.

MARX, D. H. The influence of ectotrophic mycorrhizal fungi on the resistance of pine roots to pathogenic fungi and soil bacteria. I. Antagonism of mycorrhizal fungi to root pathogenic fungi and soil bacteria. Phytopathology, Saint Paul, v. 59, p. 153-163, 1969.

MELLO, A. H. de.; ANTONIOLLI, Z. I.; SOUZA, E. L.; KAMINSKI, J. Estabelecimento a campo de mudas de Eucalyptus grandis micorrizadas com Pisolithus microparcus (UFSC Pt 116) em solo arenoso. Ciência Florestal, Santa Maria, RS, v. 19, n. 2 , p. $149-155,2009$.

MULLIGAN, C. N.; YONG, R. N.; GIBBS, B. F. Remediation technologies for metal-contaminated soils and groundwater: an evaluation. Engeneering Geology, Milano, v. 60, n. 1-4, p. $193-$ 207, 2001.

NERI, A. V.; CAMPOS, É, P. de.; DUARTE, T. G.; MEIRA NETO, J. A. A.; SILVA, A. F. da.; VALENTE, G. E. Regeneração de espécies nativas lenhosas sob plantio de Eucalyptus em área de Cerrado na Floresta Nacional de Paraopeba, MG, Brasil. Acta Botânica Brasílica, São Paulo, v. 19, n. 2, p. 369-376, 2005.

SERAFINI, L. A.; CASSEL, E. Produção de óleos essenciais: uma alternativa para a agroindústria nacional. In: SERAFINI, L. A.; BARROS, N. M.; AZEVEDO, J. L. Biotecnologia na agricultura e na agroindústria. Guaíba: Agroindústria, 2001. p. 333-377.
SMITH, S. E.; READ, D. J. Mycorrhizal symbiosis. 3rd. ed. San Diego: Academic Press, 2008. 787 p.

SOARES, C. R. F. S.; SIQUEIRA, J. O.; CARVALHO, J. G.; MOREIRA, F. M. S.; GRAZZIOTTI, P. H. Crescimento e nutrição mineral de Eucalyptus maculata e Eucalyptus urophylla em solução nutritiva com concentração crescente de cobre. Revista Brasileira de Fisiologia Vegetal, Londrina, PR, v. 12, n. 3, p. 213-225, 2000.

SOUZA, L. A. B. Seleção de fungos ectomicorrízicos eficientes para promoção do crescimento de Eucalyptus dunni Maiden. 2003. 100 f. Dissertação (Mestrado em Biotecnologia) Universidade Federal de Santa Catarina, Florianópolis.

STEFFEN, R. B.; A NTONIOLLI, Z. I.; STEFFEN, G. P. K. Efeito estimulante do óleo essencial de eucalipto na germinação e no crescimento inicial de mudas de Eucalyptus grandis. Pesquisa Florestal Brasileira, Colombo, v. 30, n. 63, p. 199-206, 2010.

TURNAU, K.; PRZYBYLOWICZ, W. J.; MESJASZPRZYBYLOWICZ, J. Heavy metal distribuition in Suillus luteus mycorrhizas: as revealed by micro-PIXE analysis. Nuclear Instruments and Methods in Physics Research, Cambridge, v. 181, p. 649-658, 2001.

VITTI, A. M. S.; BRITO, J. O. Óleo essencial de Eucalipto. Piracicaba, SP: Escola Superior de Agricultura "Luiz de Queiroz", 2003. 26 f. (Documentos, 17).

WEISS, M.; MIKOLAJEWSKI, S.; PEIPP, H.; SCHMITT, U.; SCHMIDT, J.; WRAY, V.; STRCK, D. Tissue-specific and development-dependent accumulation of phenylpropanoids in larch mycorrhizas. Plant Physiology, Urbana, v. 114, n. 1, p. 1527, 1997.

WONG, K. K. Y.; FORTIN, J. A. Root colonization and instraspecific mycobiont variation in ectomycorrhiza. Symbiosis, Philadelphia, v. 8, n. 3, p. 197-231, 1990.

YING CHU, E.; MÖLLER, M. de R. F.; CARVALHO, J. G. de. Efeitos da inoculação micorrízica em mudas de gravioleira em solo fumigado e não fumigado. Pesquisa Agropecuária Brasileira, Brasília, DF, v. 36, n. 4, p. 671-680, 2001.

ZHI-LIN, Y.; CHUAN-CHAO, D.; LIAN-QING, C. Regulation and accumulation of secondary metabolites in plant-fungus symbiotic system. African Journal of Biotechnology, Bowie, v. 6, n. 11, p. 1266-1271, 2007. 
